\title{
Inflammatory Idiopathic Myopathies: Clinical, Laboratory Features and Prognostic Observations in 118 Hispanic-Mestizo Patients
}

Bernardo Cacho ${ }^{2}$, Brenda O López-Tintos ${ }^{1}$, Rocío Orozco-Topete ${ }^{1}$, Carlos Cantu-Brito ${ }^{2}$, Guillermo S García-Ramos ${ }^{2}$, Nydia A. Lorenzana-Mendoza ${ }^{3}$ and Fernando Espinosa-Lira ${ }^{4}$

${ }^{1}$ Dermatology Department, National Institute of Medical Sciences and Nutrition Salvador Zubirán (INCMNSZ), Mexico City, Mexico

${ }^{2}$ Neurology Department, National Institute of Medical Sciences and Nutrition Salvador Zubirán (INCMNSZ), Mexico City, Mexico

${ }^{3}$ Facultad de Medicina Universidad Nacional Autónoma de México, Mexico

${ }^{4}$ Facultad Mexicana de Medicina Universidad La Salle, Mexico City, Mexico

*Corresponding author: Bernardo Cacho, Neurology Department, Instituto Nacional de Cancerología, San Fernando 22. Seccion XVI, Tlalpan, México DF. ZC 14,000; Tel: +52 (55) 2127-1049; E-mail: bernardocacho@doctor.com

Received date: May 18, 2015; Accepted date: August 26, 2015; Published date: August 31, 2015

Copyright: $\odot 2015$ Cacho B, et al. This is an open-access article distributed under the terms of the Creative Commons Attribution License, which permits unrestricted use, distribution, and reproduction in any medium, provided the original author and source are credited.

\section{Abstract}

Objective: To determine the clinical and laboratory features, malignancy, outcome and their association in a Hispanic mestizo population with Inflammatory Idiopathic Myopathies (IIM).

Material and methods: The medical records of Hispanic mestizo patients with dermatomyositis, polymyositis or overlap syndrome from a single center were reviewed. Several variables were studied with emphasis on malignancy.

Results: We report the clinical and laboratorial features of 118 patients with IIM; the female to male ratio was 2.3:1. Elevated CK, proximal weakness, compatible biopsy and elevated LDH were the most frequent findings. Malignancy was found in $9,3 \%$, gynecological tumors were the most common (55\%). Mortality was $10.2 \%$, mainly related to infections and respiratory failure.

Conclusions: The overall rate of malignancy in this large series of patients with IIM was $9.3 \%$. The majority of our patients reached a good outcome. No risk factors for malignancy were found.

Keywords: Inflammatory myopathies;

Polymyositis; Overlap syndrome; Malignancy

\section{Introduction}

Inflammatory idiopathic myopathies (IIM) include[1] dermatomyositis (DM), polymyositis (PM), overlap syndromes (OS) also referred as overlap myositis [2] - and inclusion body myositis (IBM); the first three have been associated with malignancy since last century [3], with no risk factors yet identified. Scarce reports have included a Hispanic mestizo population [4]. The aim of this large series is to describe the clinical and laboratory features of IIM, the frequency of malignancy and associated risk factors in a Hispanic mestizo population.

The old criteria of Peter and Behan proposed in 1975 have served the community well for years but cannot explain the differences in the subsets of inflammatory myopathies $[5,6]$. Troyanov et al. developed an interesting clinicoserologic classification where overlap clinical features as well as myositis-associated autoantibodies (MAAs) and myositis specific autoantibodies (MSAs) were positioned at the core of the classification system [2]. One major difficulty, both in terms of diagnosis and classification, is that it excludes the now recognized IBM, most likely incorporating those cases in the PM subgroup. Likewise, IBM was not included in the new clinicoserologic classification of IIM by Troyanov et al., or in the last European Neuromuscular Centre (ENMC) international workshop on adult IIM.

\section{Materials and Methods}

At a single referral center, a retrospective review of the records from patients with the diagnosis of IIM was made from 1986-2004; we excluded patients with age $<15$ years (the hospital treats only adult patients), incomplete or unclear diagnosis or data and follow up $<1$ year. We studied the following: demographic information, type of IIM, weakness at onset, signs of systemic involvement (fever, weight loss or both), Raynaud's phenomena, cutaneous findings (heliotropic rash, Gottron papules, malar erythema, poikiloderma, periungeal teleangiectasias, V sign, Shawl sign), serum levels of creatine kinase (CK), Complete Blood Count (CBC), Creatinine (Cr), Erythrocyte Sedimentation Rate (ESR), Albumin (Alb), Lactate Dehydrogenase (LDH), Antinuclear Antibodies (ANA); Electromyographic findings (EMG), muscle biopsy features (fiber atrophy, inflammation, nuclear internalization, blood vessel wall infiltration, necrosis), a modified functional disability score [7], mortality and cause of death; association and type of malignancy, follow-up. The diagnosis of definite/probable/possible myositis were according to the Bohan and Peter $[5,6]$ criteria, and the clinical overlap features were defined as described by Troyanov et al., for this reason, inclusion body myositis (IBM) was excluded based on previously accepted criteria [8-10]. Institutional Research Committee approved the study. 
Citation: Cacho B, López-Tintos BO, Orozco-Topete R, Cantu-Brito C, García-Ramos GS, et al. (2015) Inflammatory Idiopathic Myopathies: Clinical, Laboratory Features and Prognostic Observations in 118 Hispanic-Mestizo Patients. J Neurol Neurophysiol 6: 313. doi:

Page 2 of 5

\section{Results}

We report the findings of 118 patients; 74 (63\%) with DM, 20 (17\%) PM and 24 (20\%) OS. There were 83 women (70\%) and 35 men; the female to male ratio was 2.3:1. Mean age was 37 years (IQR 24-49 years). The mean follow up was 68.3 months (range 14-97 months). Table 1 describes demographic, clinical and laboratory features accordingly to type of IIM.

\begin{tabular}{|c|c|c|c|}
\hline & DM & PM & os \\
\hline & $74(100 \%)$ & $20(100 \%)$ & $24(100 \%)$ \\
\hline Age (mean $\pm S D$; Range $15-70$ ), years & $35.01 \pm 15.43$ & $41.45 \pm 12.1$ & $41.88 \pm 15.54$ \\
\hline Female & $50(68)$ & $15(75)$ & $18(75 \%)$ \\
\hline Male & $24(32)$ & $5(25)$ & $6(25 \%)$ \\
\hline Follow-up (mean $\pm \mathrm{SD}$ ), months & $61.64 \pm 56.1$ & $76.4 \pm 63.67$ & $82.42 \pm 73.93$ \\
\hline \multicolumn{4}{|l|}{ Diagnostic Criteria } \\
\hline Proximal weakness & $73(99 \%)$ & $20(100 \%)$ & $24(100 \%)$ \\
\hline High CK UI/L (>263) & $61 / 73(84 \%)$ & 19/20 (95\%) & 18/23 (78\%) \\
\hline Myopathic changes on EMG & $49 / 50(98 \%)$ & 16/16 (100\%) & $13 / 15(87 \%)$ \\
\hline Muscle biopsy & $3 / 52(6 \%)$ & $3 / 16(19 \%)$ & 0 \\
\hline Normal & $2 / 52(4 \%)$ & 0 & $1 / 20(5 \%)$ \\
\hline Atrophy & $4 / 52(8 \%)$ & $1 / 16(6 \%)$ & $3 / 20(15 \%)$ \\
\hline Inespecific regeneration & $43 / 52(83 \%)$ & $12 / 16(75 \%)$ & $16 / 20(80 \%)$ \\
\hline \multicolumn{4}{|l|}{ Compatible } \\
\hline Cutaneous findings & $74(100 \%)$ & 0 & $12(50 \%)$ \\
\hline Bohan and Peter & $57(77 \%)$ & $11(55 \%)$ & $14(58 \%)$ \\
\hline Definite & $16(22 \%)$ & $6(30 \%)$ & $8(33 \%)$ \\
\hline Probable & $1(1 \%)$ & $3(15 \%)$ & $2(8 \%)$ \\
\hline \multicolumn{4}{|l|}{ Possible } \\
\hline \multicolumn{4}{|l|}{ Other clinical features: } \\
\hline Systemic symptoms & $36(49 \%)$ & $15(75 \%)$ & $13(54 \%)$ \\
\hline Weight loss only $>5 \%$ & $23(31 \%)$ & $11(55 \%)$ & $7(29 \%)$ \\
\hline Fever only & $4(5 \%)$ & 0 & $1(4 \%)$ \\
\hline Both & $9(12 \%)$ & $4(20 \%)$ & $5(21 \%)$ \\
\hline Raynaud's phenomenon & $14(19 \%)$ & $1(5 \%)$ & $8(33 \%)$ \\
\hline \multicolumn{4}{|l|}{ Other laboratory data: } \\
\hline High LDH (>164 UI/L) & $62 / 70(89 \%)$ & $19 / 19(100 \%)$ & $20 / 24(83 \%)$ \\
\hline Low Hemoglobin (<14 g/dL) & $26(35 \%)$ & $6(30 \%)$ & $12(50 \%)$ \\
\hline Low Albumin $(<3.5 \mathrm{~g} / \mathrm{dL})$ & $31 / 70(44 \%)$ & $5 / 18(28 \%)$ & $14 / 24(58 \%)$ \\
\hline Elevated ESR & $26 / 69(38 \%)$ & $4 / 18(22 \%)$ & $12 / 21(57 \%)$ \\
\hline Positive ANA & $33 / 62(53 \%)$ & $4 / 17(24 \%)$ & $17 / 21(81 \%)$ \\
\hline
\end{tabular}

Table 1: Demographic, clinical and laboratory findings in 118 patients with Dermatomyositis (DM), Polymyositis (PM) or overlap syndrome (OS).

According to Bohan and Peter's criteria, $69.5 \%$ had definite diagnosis, $25.5 \%$ probable and $5 \%$ possible. Proximal weakness was present at the time of diagnosis in $99 \%$. As systemic manifestations of the disease, $35 \%$ had weight loss only $>5 \%$, $4.2 \%$ fever only and $15.3 \%$ both. 
Citation: Cacho B, López-Tintos BO, Orozco-Topete R, Cantu-Brito C, García-Ramos GS, et al. (2015) Inflammatory Idiopathic Myopathies: Clinical, Laboratory Features and Prognostic Observations in 118 Hispanic-Mestizo Patients. J Neurol Neurophysiol 6: 313. doi: $10.4172 / 2155-9562.1000313$

Page 3 of 5

Characteristic dermatologic findings were found in $73 \%$ of the patients, $100 \%$ in those with DM, $0 \%$ PM and $50 \%$ of OS. Raynaud's phenomenon was present in $19.5 \%$ of the patients. Of the 24 patients with OS, according clinical overlap features described by Troyanov et al., 6 (25\%) had mixed connective tissue disease, 6 (25\%) rheumatoid arthritis, 4 (17\%) scleroderma, 4 (17\%) Sjögren's disease and $4(17 \%)$ lupus.

Laboratory features included an elevated CK in $84.4 \%$, high LHD in $90 \%$, seric hemoglobin levels and albumin were low in $37 \%$ and $45 \%$ respectively, creatinine elevation was seen in only $0.8 \%$, and high ESR was detected in $39 \%$. ANA were positive in $54 \%$ of the studied population.

The electromyography showed a myopathic pattern (increased insertional and spontaneous activity in the form of potentials positive sharp waves, and complex repetitive discharges, and low-amplitude, short-duration polyphasic motor unit action potentials) in $96 \%$.
Muscle biopsy showed a compatible diagnosis (Dermatomyositis: perifascicular atrophy, or at least two of reduced capillary density, perivascular and/or perimysial inflammatory cell infiltrate; Polymyositis: endomysial inflammatory T-cells surrounding and invading non-necrotic muscle fibers, exclusion of necrotizing myopathies and dystrophies) with IIM in $81 \%$, regeneration $9 \%$, normal $7 \%$, atrophy $3 \%$.

Malignancy was diagnosed in 11 (9.3\%) patients (Table 2). Location included uterine cervix in 4 , unknown primary in 2 , salivatory gland in 1 , endometrial 1 , ovary 1 , urinary tract 1 , cecal appendix 1 . According to histopathological findings, 5 were epidermoid carcinomas and 6 adenocarcinomas. All were suspected during an initial clinical evaluation. No differences between the groups were found.

\begin{tabular}{|c|c|c|c|c|}
\hline & $\begin{array}{l}\mathrm{DM} \\
\mathrm{N}=74\end{array}$ & $\begin{array}{l}P M \\
n=20\end{array}$ & $\begin{array}{l}\text { OS } \\
n=24\end{array}$ & $\begin{array}{l}\text { Total } \\
\mathrm{n}=118\end{array}$ \\
\hline Malignancy & $6(8 \%)$ & $3(15 \%)$ & $2(8.3 \%)$ & $11(9.3 \%)$ \\
\hline Before the diagnosis of IIM & 1 & - & - & 1 \\
\hline After the diagnosis of IIM & 5 & 3 & 2 & 10 \\
\hline $\begin{array}{l}\text { Location of malignancy } \\
\text { Cervix } \\
\text { Endometrium } \\
\text { Ovary } \\
\text { Urinary Tract } \\
\text { Cecal appendix } \\
\text { Unknown primary } \\
\text { Salivatory gland }\end{array}$ & $\begin{array}{l}1 \\
1 \\
1 \\
- \\
1 \\
2 \\
-\end{array}$ & $\begin{array}{l}1 \\
- \\
- \\
1 \\
- \\
- \\
1\end{array}$ & $\begin{array}{l}2 \\
- \\
- \\
- \\
- \\
- \\
-\end{array}$ & $\begin{array}{l}4 \\
1 \\
1 \\
1 \\
1 \\
2 \\
1\end{array}$ \\
\hline $\begin{array}{l}\text { Histological variant } \\
\text { Adenocarcinoma } \\
\text { Epidermoid }\end{array}$ & $\begin{array}{l}4 \\
2\end{array}$ & $\begin{array}{l}1 \\
2\end{array}$ & $\begin{array}{l}1 \\
1\end{array}$ & $\begin{array}{l}6 \\
5\end{array}$ \\
\hline
\end{tabular}

Table 2: Malignancy characteristics in 118 patients with Dermatomyosytis (DM), Polymyositis (PM) or Overlap Syndrome (OS).

Treatment and outcome are shown in Table 3,corticosteroids were used in $97.5 \%$ of the patients, a dose $>40 \mathrm{mg} /$ day was needed in $73 \%$; concomitant use of cytotoxic drugs were prescribed in $82 \%$, methotrexate was the most commonly used (41\%), followed by azathioprine in $32 \%$, both in $21 \%$ and cyclophosphamide $6 \%$. Chloroquine was used in $26 \%$, most frequently to treat DM ( $87 \%)$.

\begin{tabular}{|c|c|c|c|}
\hline & $\begin{array}{l}\text { DM } \\
n=74(\%)\end{array}$ & $\begin{array}{l}P M \\
n=20(\%)\end{array}$ & $\begin{array}{l}\text { OS } \\
n=24(\%)\end{array}$ \\
\hline Prednisone & $71(96)$ & $20(100)$ & $24(100)$ \\
\hline$<40 \mathrm{mg} /$ day & $17(23)$ & $3(15)$ & $9(37)$ \\
\hline$>40$ mg/day & $54(73)$ & $17(85)$ & $15(63)$ \\
\hline Cytotoxic drugs & $63(85)$ & $16(80)$ & $18(75)$ \\
\hline MTX $<15 \mathrm{mg} /$ week & $18(24)$ & $7(35)$ & $4(17)$ \\
\hline MTX $>15 \mathrm{mg} /$ week & $7(10)$ & $2(10)$ & $2(8)$ \\
\hline$A Z A<50 \mathrm{mg} /$ day & 0 & 0 & $2(8)$ \\
\hline
\end{tabular}

\begin{tabular}{|l|l|l|l|}
\hline AZA >50 mg/day & $22(30)$ & $2(10)$ & $5(21)$ \\
Both & $12(16)$ & $4(20)$ & $4(17)$ \\
Cyclophosphamide & $4(5)$ & $1(5)$ & $1(4)$ \\
\hline Chloroquine & 37 & 20 & 0 \\
\hline Functional status at first visit & $3(4)$ & $1(5)$ & 0 \\
I & $32(43)$ & $7(35)$ & $9(37)$ \\
II & $30(41)$ & $11(55)$ & $11(46)$ \\
III & $9(12)$ & $1(5)$ & $4(17)$ \\
IV & 0 & 0 & 0 \\
V & & $13(65)$ & $16(67)$ \\
\hline Functional status at last visit & $55(74)$ & $5(25)$ & $3(12)$ \\
I & $8(11)$ & $1(5)$ & 0 \\
II & $2(3)$ & 0 & $1(4)$ \\
III & $2(3)$ & & \\
IV & & & \\
\hline
\end{tabular}


Citation: Cacho B, López-Tintos BO, Orozco-Topete R, Cantu-Brito C, García-Ramos GS, et al. (2015) Inflammatory Idiopathic Myopathies: Clinical, Laboratory Features and Prognostic Observations in 118 Hispanic-Mestizo Patients. J Neurol Neurophysiol 6: 313 . doi: $10.4172 / 2155-9562.1000313$

Page 4 of 5

\begin{tabular}{|l|l|l|l|}
\hline $\mathrm{V}$ & $7(9)$ & $1(5)$ & $4(17)$ \\
\hline Response to therapy & $63(85)$ & $18(90)$ & $19(79)$ \\
\hline Death & $7(9)$ & $1(5)$ & $4(17)$ \\
\hline Cause of death & $3 / 7(43)$ & $1 / 1(100)$ & $2 / 5(40)$ \\
Infections & $1 / 7(14)$ & 0 & 0 \\
Respiratory failure & $2 / 7(29)$ & 0 & $1 / 5(20)$ \\
Malignancy & $1 / 7(14)$ & 0 & $1 / 5(20)$ \\
Unknown & 0 & 0 & $1 / 5(20)$ \\
Cardiovascular & & & \\
\hline
\end{tabular}

Table 3: Treatment and outcome in 118 patients with Dermatomyositis (DM), Polymyositis (PM) and Overlap Syndrome (OS),

The functional status (FS) at admission was I, II, III, IV and V in 3, $41,44,12$ and $0 \%$ in that order, the FS during the last reported visit was I, II, III, IV and V in 71, 14, 2.5, 2.5 and $10.2 \%$ equally.

The mortality in our series was $10.2 \%$. The most common cause were lower respiratory tract (LRT) infections (50\%), malignancy (25\%), and other determined causes included respiratory failure due to weakness or aspiration and cardiovascular disorders.

\section{Discussion}

In order to make a more reliable diagnosis of IIM, as suggested by many [11-17] we included only patients who had a complete diagnostic work-up; this included a re-review of the muscle specimens that were available (88/118) [18].

All our patients with DM had featured cutaneous findings described elsewhere [19-22] and none had amyopathic dermatomyositis as anticipated [23].

The overall frequency of malignancy in patients with IIM varies, according to geographical area and racial trait studied, from $6-45 \%$ $[1,8,24-29]$. In our series 6 of 74 patients (8\%) with DM, 3 of $20(15 \%)$ with PM and 2 of $24(8 \%)$ with OS had malignancy. If we excluded cervix uteri as an associated malignancy, the frequency would be 7,10 and $0 \%$ correspondingly; these results are comparable to the aforementioned reports. Cancer types varies among different series, in ours uterine/cervical cancer was the most common, even if we discarded the association of this neoplasm with the disease[26,28] an incidence of $5 \%$ should draw our attention to this co-morbidity. Other sites of neoplasm, in our studied population, included mainly genitourinary tract (endometrium, ovary, ureter), 2 were found in the GI tract (salivatory gland, cecal appendix) and no site was evidenced in 2. One patient had the diagnosis of malignancy (cecal appendix) before the IIM was evident, and for the rest, a latency of 1 to 39 months was required; the temporal association of malignancy with IIM has been considered of outmost importance in order to consider the IIM as paraneoplastic disorders [28,29]. Some rheumatic diseases [29-31], as well as the IIM have reported a high incidence of malignancy; clinical and laboratorial actions should be taken, to make a prompt diagnosis and adequate treatment. To achieve the diagnosis of malignancy, clinical examination and routine tests sufficed in 11/12, CT scan was the preferred method for sustaining the diagnosis of malignancy besides the obligatory pathological confirmation. Routine examination

and in some cases a CT scan might be enough to search for malignancy in patients with IIM [32].

The mortality in this series (10\%) is comparable to what others have found [29, 33-36], and infectious disease was the main cause in ours.

Conventional treatment of the patients [37-39] was mainly based on corticosteroids, chloroquine and/or steroid sparing agents.

Functional status was assessed by a modified Functional Disability Score [7], we added a Grade V for death, this scale was used because it is easy to document and there has not been any universally accepted system or criteria [40]. Response to therapy, defined as an improvement in functional status and good outcome, defined as a FS grade I or II, was reached in $85 \%$ as seen in other centers [36,41,42].

We searched among the studied variables for risk factors that predicted malignancy, none were found, as seen in table 4. For mortality, the use of cytotoxic drugs was the only variable that reached statistical significance, patients who did not used these medications died more frequently (7/21) than those who did (5/97), the significance of this is yet to be elucidated. Finally, a referral basis must be taken into account.

\begin{tabular}{|l|l|l|l|l|}
\hline & \multicolumn{2}{|l|}{ Malignancy n (\%) } & \multicolumn{2}{l|}{ Death n (\%) } \\
\hline & Yes & No & Yes & No \\
\hline DM & $6(8.1)$ & $68(91.9)$ & $7(9.5 \%)$ & $67(90.5 \%)$ \\
\hline PM & $3(15)$ & $17(85)$ & $1(5)$ & $19(95)$ \\
\hline OS & $2(8.3)$ & $22(91.7)$ & $4(16.7)$ & $20(83.3)$ \\
\hline Female & $9(10.8)$ & $74(89.2)$ & $7(8.4)$ & $76(91.6)$ \\
\hline Male & $2(5.7)$ & $33(94.3)$ & $5(14.3)$ & $30(85.7 \%)$ \\
\hline High CPK & $11(11.2)$ & $87(88.8)$ & $9(9.2)$ & $89(90.8)$ \\
\hline Cutaneous signs & $7(8.1)$ & $79(91.9)$ & $9(10.5)$ & $77(89.5)$ \\
\hline Raynaud phenomenon & 0 & $23(100)$ & $3(13)$ & $20(87)$ \\
\hline Low Hb & $4(9.1)$ & $40(90.9)$ & $3(6.8)$ & $41(93.2)$ \\
\hline High Cr & 0 & $1(100)$ & 0 & $1(100 \%)$ \\
\hline Low Alb & $4(8)$ & $46(92)$ & $7(14)$ & $43(86)$ \\
\hline High LDH & $11(10.9)$ & $90(89.1)$ & $10(9.9)$ & $91(90.1)$ \\
\hline High ESR & $3(7.1)$ & $39(92.9)$ & $4(9.5)$ & $38(90.5)$ \\
\hline Corticosteroid use & $11(9.4)$ & $104(90.4)$ & $10(8.7)$ & $105(91.3)$ \\
\hline Cytotoxic drugs use & $6(6.2)$ & $91(93.8)$ & $5(5.2)$ & $92(94.8)$ \\
\hline Chloroquine use & $29(93.5)$ & $1(3.2)$ & $30(96.8)$ \\
\hline
\end{tabular}

Table 4: Analyzed risk factors for malignancy and mortality.

\section{Conclusion}

In a mestizo-hispanic population with IIM treated at our center, the frequency of malignancy was $9.3 \%$. The majority of our patients reached a good outcome. A mortality of $10 \%$ was observed, with LRT infections being the most common cause. No risk factors for malignancy were found. 
Citation: Cacho B, López-Tintos BO, Orozco-Topete R, Cantu-Brito C, García-Ramos GS, et al. (2015) Inflammatory Idiopathic Myopathies: Clinical, Laboratory Features and Prognostic Observations in 118 Hispanic-Mestizo Patients. J Neurol Neurophysiol 6: 313. doi: 10.4172/2155-9562.1000313

Page 5 of 5

\section{References}

1. Amato AA, Greenberg SA (2006) Inflammatory myopathies. Continuum lifelong learning in neurology 12: 140-168.

2. Troyanov Y, Targoff IN, Tremblay JL, Goulet JR, Raymond Y, et al. (2005) Novel classification of idiopathic inflammatory myopathies based on overlap syndrome features and autoantibodies: analysis of 100 French Canadian patients. Medicine (Baltimore) 84: 231-249.

3. Stertz G (1916) Polymyositis. Berl Klin Wochenschr 53: 489

4. García de la Torre I (2008) Polimiositis y dermatomiositis. Rev Mex Reumat 17: 195-198.

5. Bohan A, Peter JB (1975) Polymyositis and dermatomyositis (first of two parts). N Engl J Med 292: 344-347.

6. Bohan A, Peter JB (1975) Polymyositis and dermatomyositis (second of two parts). N Engl J Med 292: 403-407.

7. Henriksson KG, Sandstedt P (1982) Polymyositis--treatment and prognosis. A study of 107 patients. Acta Neurol Scand 65: 280-300.

8. Griggs RC, Askanas V, DiMauro S, Engel A, Karpati G, et al. (1995) Inclusion body myositis and myopathies. Ann Neurol 38: 705-713.

9. Badrising UA, Maat-Schieman M, van Duinen SG, Breedveld F, van Doorn P, et al. (2000) Epidemiology of inclusion body myositis in the Netherlands: a nationwide study. Neurology 55: 1385-1387.

10. Engel WK, Askanas V (2006) Inclusion-body myositis: Clinical, diagnostic, and pathologic aspects. Neurology 66: S20-29.

11. Amato AA, Barohn RJ (1997) Idiopathic inflammatory myopathies. Neurol Clin 15: 615-648.

12. Callen JP (2000) Dermatomyositis. Lancet 355: 53-57.

13. Dalakas MC, Hohlfeld R (2003) Polymyositis and dermatomyositis. Lancet 362: 971-982.

14. Hoogendjik JE, Amato AA, Lecky BR, Choy EH, Lundberg IE, et al. (2004) 119th ENMC international workshop: trail design in adult idiopathic inflammatory myopathies, with the exception of inclusion body myositis, 10-12 October 2003; naarden. The Netherlands. Neuromuscul Disord 14: 337-345.

15. Mastaglia FL, Phillips BA (2002) Idiopathic inflammatory myopathies: epidemiology, classification, and diagnostic criteria. Rheum Dis Clin North Am 28: 723-741.

16. Rendt K (2001) Inflammatory myopathies: Narrowing the differential diagnosis. Cleve Clin J Med 68: 505, 509-514, 517-9.

17. Amato AA, Griggs RC (2003) Unicorns, dragons, polymyositis, and other mythological beasts. Neurology 61: 288-289.

18. Dalakas MC (2002) Muscle biopsy findings in inflammatory myopathies. Rheum Dis Clin North Am 28: 779-798.

19. Dourmishev LA, Dourmishev AL, Schwartz RA (2002) Dermatomyositis: Cutaneous manifestations of its variants. Int J Dermatol 41: 625-630.

20. Sontheimer RD (1999) Cutaneous features of classic dermatomyositis and amyopathic dermatomyositis. Curr Opin Rheumatol 11: 475-482.

21. Sontheimer RD (2002) Dermatomyositis: an overview of recent progress with emphasis on dermatologic aspects. Dermatol Clin 20: 387-408.

22. Koler RA, Montemarano A (2001) Dermatomyositis. Am Fam Physician 64: 1565-1572.

23. Gerami P, Schope JM, McDonald L, Walling HW, Sontheimer (2006) A systematic review of adult-onset clinically amyopathic dermatomyositis (dermatomyositis siné myositis): A missing link within the spectrum of the idiopathic inflammatory myopathies. J Am Acad Dermatol 54: 597-613.

24. Airio A, Pukkala E, Isomäki H (1995) Elevated cancer incidence in patients with dermatomyositis: A population based study. J Rheumatol 22: $1300-1303$

25. Buchbinder R, Forbes A, Hall S, Dennett X, Giles G (2001) Incidence of malignant disease in biopsy-proven inflammatory myopathy. A population-based cohort study. Ann Intern Med 134: 1087-1095.

26. Callen JP (1994) Myositis and malignancy. Curr Opin Rheumatol 6: 590-594.

27. Hill CL, Zhang Y, Sigurgeirsson B, Pukkala E, Mellemkjaer L, et al. (2001) Frequency of specific cancer types in dermatomyositis and polymyositis: A population-based study. Lancet 357: 96-100.

28. Stockton D, Doherty VR, Brewster DH (2001) Risk of cancer in patients with dermatomyositis or polymyositis, and follow-up implications: A Scottish population-based cohort study. Br J Cancer 85: 41-45.

29. Sigurgeirsson B, Lindelöf B, Edhag O, Allander E (1992) Risk of cancer in patients with dermatomyositis or polymyositis. A population-based study. N Engl J Med 326: 363-367.

30. Levine SM (2006) Cancer and myositis: new insights into an old association. Curr Opin Rheumatol 18: 620-624.

31. Leandro MJ, Isenberg DA (2001) Rheumatic diseases and malignancy--is there an association? Scand J Rheumatol 30: 185-188.

32. Sparsa A, Liozon E, Herrmann F, Ly K, Lebrun V, et al. (2002) Routine vs. extensive malignancy search for adult dermatomyositis and polymyositis: A study of 40 patients. Arch Dermatol 138: 885-890.

33. Bronner IM, van der Meulen MF, de Visser M, Kalmijn S, van Venrooij WJ, et al. (2006) Long-term outcome in polymyositis and dermatomyositis. Ann Rheum Dis 65: 1456-1461.

34. Dankó K, Ponyi A, Constantin T, Borgulya G, Szegedi (2004) Long-term survival of patients with idiopathic inflammatory myopathies according to clinical features: a longitudinal study of 162 cases. Medicine 83: 35-42.

35. Marie I, Hachulla E, Hatron PY, Hellot MF, Levesque H, et al. (2001) Polymyositis and dermatomyositis: short term and longterm outcome, and predictive factors of prognosis. J Rheumatol 28: 2230-2237.

36. Ponyi A, Borgulya G, Constantin T, Váncsa A, Gergely L, et al. (2005) Functional outcome and quality of life in adult patients with idiopathic inflammatory myositis. Rheumatology (Oxford) 44: 83-88.

37. Dalakas MC (1994) Current treatment of the inflammatory myopathies. Curr Opin Rheumatol 6: 595-601.

38. Di Martino SJ, Kagen LJ (2006) Newer therapeutic approaches: inflammatory muscle disorders. Rheum Dis Clin North Am 32: 121-128.

39. Oddis CV (2002) Idiopathic inflammatory myopathy: management and prognosis. Rheum Dis Clin North Am 28: 979-1001.

40. Dayal NA, Isenberg DA (2001) Assessment of inflammatory myositis. Curr Opin Rheumatol 13: 488-492.

41. Sultan SM, Ioannou Y, Moss K, Isenberg DA (2002) Outcome in patients with idiopathic inflammatory myositis: morbidity and mortality. Rheumatology (Oxford) 41: 22-26.

42. Wigley FM (2002) Clinical practice. Raynaud's Phenomenon. N Engl J Med 347: 1001-1008. 